Provided for non-commercial research and education use. Not for reproduction, distribution or commercial use.

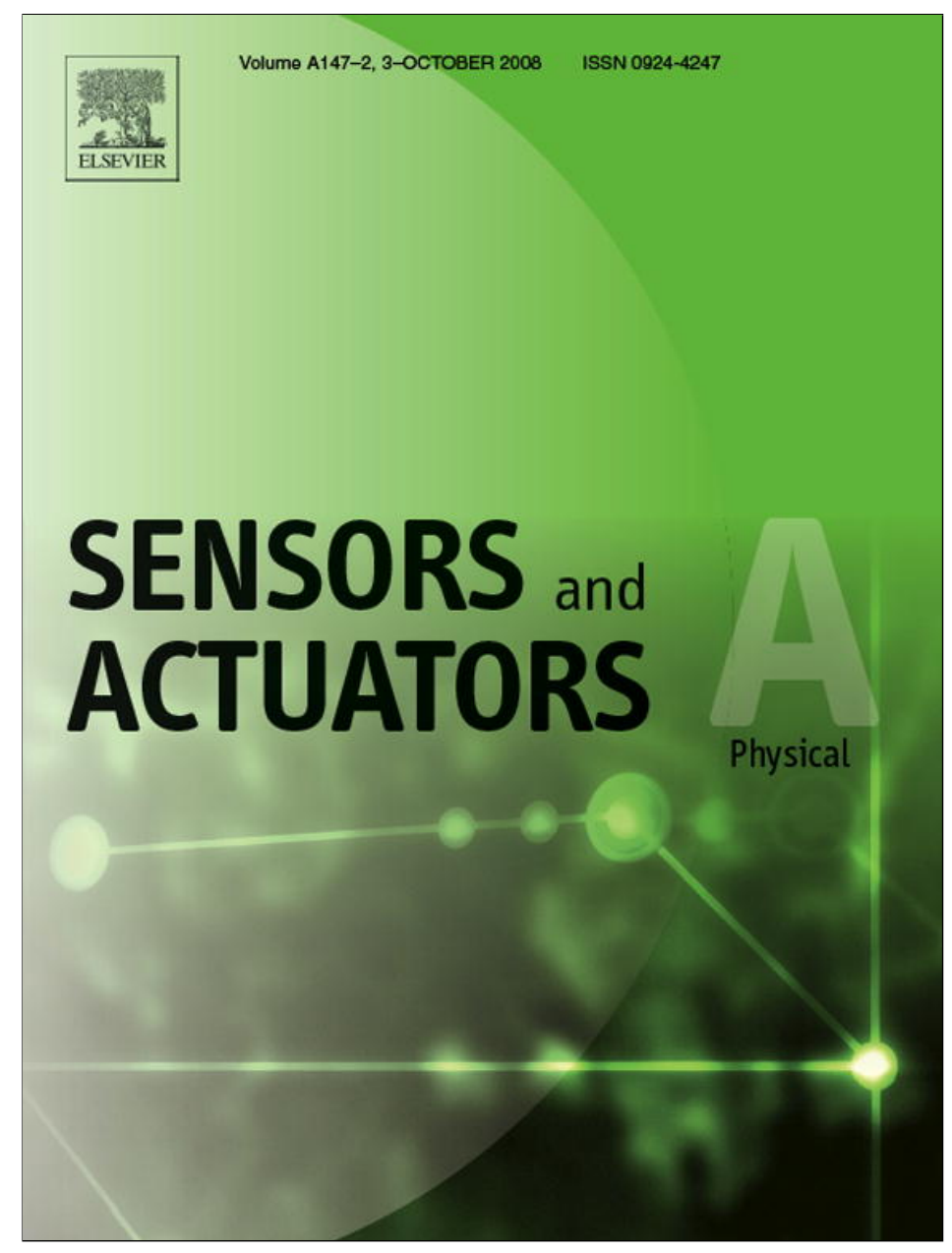

This article appeared in a journal published by Elsevier. The attached copy is furnished to the author for internal non-commercial research and education use, including for instruction at the authors institution and sharing with colleagues.

Other uses, including reproduction and distribution, or selling or licensing copies, or posting to personal, institutional or third party websites are prohibited.

In most cases authors are permitted to post their version of the article (e.g. in Word or Tex form) to their personal website or institutional repository. Authors requiring further information regarding Elsevier's archiving and manuscript policies are encouraged to visit:

http://www.elsevier.com/copyright 


\title{
Temperature offset drift of GMI sensors
}

\author{
Michal Malátek $^{\mathrm{a}, \mathrm{b}, *}$, Pavel Ripka ${ }^{\mathrm{a}, 1}$, Luděk Kraus ${ }^{\mathrm{b}, 2}$ \\ a Faculty of Electrical Engineering, CTU in Prague, Technická 2, CZ-16627 Praha 6, Czech Republic \\ ${ }^{\mathrm{b}}$ Institute of Physics, ASCR, Na Slovance 2, CZ-18221 Praha 8, Czech Republic
}

\section{A R T I C L E I N F O}

\section{Article history:}

Received 8 February 2008

Received in revised form 30 April 2008

Accepted 2 May 2008

Available online 18 May 2008

\section{Keywords:}

Giant magnetoimpedance

Magnetic sensor

Temperature stability

\begin{abstract}
A B S T R A C T
Temperature offset stability of magnetoimpedance sensor is discussed based on experiments accomplished with soft magnetic amorphous material. An amorphous ribbon of $\mathrm{Co}_{67} \mathrm{Fe}_{4} \mathrm{Cr}_{7} \mathrm{Si}_{8} \mathrm{~B}_{14}$ composition was tested in a magnetic shield with adjustable internal temperature. DC resistance and complex components of impedance at frequencies up to $30 \mathrm{MHz}$ were investigated in the temperature range of -20 to $+75^{\circ} \mathrm{C}$. The measured data were used for the evaluation of temperature dependence of transverse permeability that is assumed to be a major contributor to the temperature variations of impedance. We also show that thermal treatments of the amorphous ribbon significantly affect the temperature behaviour of GMI. In case of tested alloy, which has very small negative temperature coefficient of resistivity, the achieved equivalent temperature offset drift is $-0.27 \mathrm{~A} / \mathrm{m} / \mathrm{K}$ $(-340 \mathrm{nT} / \mathrm{K})$.
\end{abstract}

(C) 2008 Elsevier B.V. All rights reserved.

\section{Introduction}

Giant magnetoimpedance (GMI) has been a well-studied phenomenon since half of nineties of the last century. The drastic change of complex impedance of ferromagnetic conductor upon the application of magnetic field was believed to be very suitable for wide range of applications in sensors [1]. Some practical applications have been developed by several laboratories (see [2-6]). Moreover, some sensors are already commercially available [7]. The research is mostly focused to exploitable features of the effect as the sensitivity to tensile stress [8] and torque [9] but does not deal much with parasitic temperature dependence that might strongly limit the practical utilisation of newly developed MI materials and structures in sensing devices. The importance of investigation of temperature stability arises even more in case of amorphous and nanocrystalline $\mathrm{Co}$ - and Fe-rich alloys with low-Curie temperature (lying usually between 200 and $400^{\circ} \mathrm{C}$ ).

Among the most important sensor properties belong sensitivity, offset and their stability. In case of GMI sensors these parameters are given mainly by the properties of ferromagnetic material used.

\footnotetext{
* Corresponding author at: Faculty of Electrical Engineering, Department of Measurement, CTU in Prague, Technická 2, CZ-16627 Praha 6, Czech Republic.

Tel.: +420 224352178/266052877; fax: +420 233339929/286890527.

E-mail addresses: michal@toulavymedved.cz (M. Malátek),ripka@fel.cvut.cz

(P. Ripka), kraus@fzu.cz (L. Kraus).

1 Tel.: +420 224352178; fax: +420 233339929 .

2 Tel.: +420 266052174; fax: +420 286890527.
}

The offset drift of the basic GMI sensor is defined as the drift of impedance when the measured quantity is zero. The sensitivity is defined as the slope of quasi-linear part of GMI characteristic, the $Z(H)$ curve. Both parameters depend on many external effects such as mechanical stresses, and also the temperature influence of impedance of the ferromagnetic conductor. Indeed, there are some fabrication techniques that can suppress the influence of parasitic agents. For example, magnetostriction constant and sensitivity to stress can be tailored by Joule heating [10]. Annealing under applied magnetic field and/or stress can decrease the sensitivity to transversal magnetic field (inducing suitable magnetic anisotropy. However, these fabrication techniques do not solve the problem of temperature stability of GMI effect.

Despite of marginal attention devoted to the temperature tests, few works appeared triggered by Kim et al. who reported on GMI behaviour of Co-rich ribbons in a "low-temperature environment" (from 10 to $300 \mathrm{~K}$ ) [11]. Later on, first investigations of the temperature stability with respect to the annealing procedure were achieved on Co-rich material by Jiang et al. [12]. However, the temperature span still remained at the "low temperatures". Tehranchi et al. pushed the range towards more conventional temperatures when comparing GMI behaviour of as-cast and Joule-heat annealed Co-rich ribbons in temperatures from -170 to $+60^{\circ} \mathrm{C}$ [13]. Honkura [14] and Malátek et al. [15] discuss stability of single- and double-core GMI sensors in temperatures up to $+80^{\circ} \mathrm{C}$. Some more improvements of GMI sensors appeared also in Refs. [16,17].

This paper deals with the offset changes of the GMI effect and GMI sensors within the "conventional" industrial temperature range (from -20 to $+75^{\circ} \mathrm{C}$ ). 


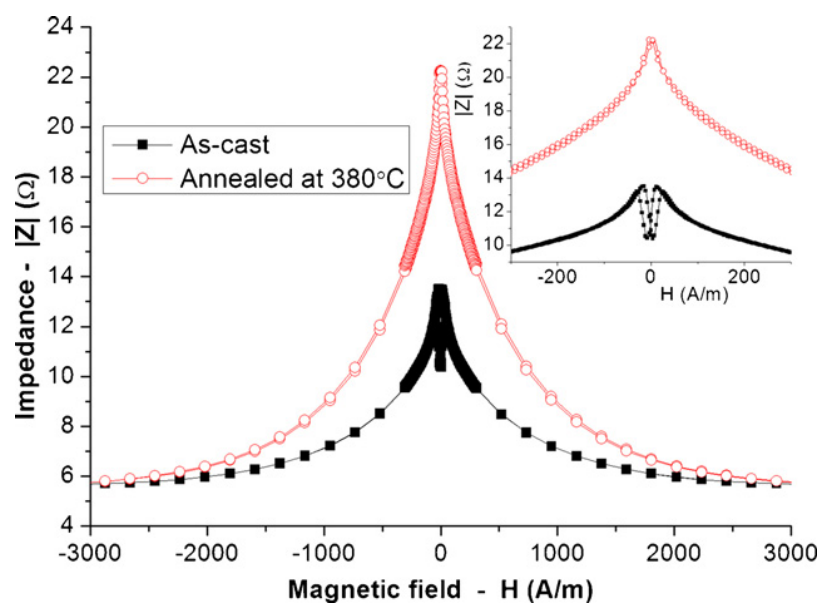

Fig. 1. GMI response- $Z(H)$ curve @ $1 \mathrm{MHz}$ of both as-cast (full squares) and annealed (empty circles) $\mathrm{Co}_{67} \mathrm{Fe}_{4} \mathrm{Cr}_{7} \mathrm{Si}_{8} \mathrm{~B}_{14}$ ribbon. A narrow-field detail of the response is shown in the inset.

\section{Experiments}

\subsection{Samples preparation}

Amorphous ribbon of $\mathrm{Co}_{67} \mathrm{Fe}_{4} \mathrm{Cr}_{7} \mathrm{Si}_{8} \mathrm{~B}_{14}$ composition, $17 \mu \mathrm{m}$ thick and $1.2 \mathrm{~mm}$ wide, was prepared by planar flow-casting at the Institute of Physics of the Slovak Academy of Sciences. In order to improve the GMI characteristics the samples of $11 \mathrm{~cm}$ in length were annealed for $10 \mathrm{~min}$ at $380^{\circ} \mathrm{C}$ under the axial magnetic field of $2400 \mathrm{~A} / \mathrm{m}$. After such treatment the ribbon remains amorphous. The GMI responses of the as-cast and the annealed samples measured at $1 \mathrm{MHz}$ are shown in Fig. 1 and their details in vicinity of zero field are depicted in the inset. The field annealing induces longitudinal anisotropy in the material (easy magnetisation axis aligned with the ribbon axis), which results in the change of GMI from the "double-peak" (full squares) to the "single-peak" (empty circles) behaviour. The GMI properties were also improved due to the relaxation of inhomogeneous internal stresses introduced by the rapid quenching. The magnetoimpedance ratio (MIR) defined as in Eq. (1) increased from $141 \%$ to $300 \%$ at the frequency of $1 \mathrm{MHz}$ :

$\operatorname{MIR}=100 \times \frac{Z(H)-Z\left(H_{\max }\right)}{Z\left(H_{\max }\right)}$

$H_{\text {max }}$ is that large magnetic field that it nearly saturates the GMI effect, hence the impedance $Z\left(H_{\max }\right)$ approaches the value of nonferromagnetic conductor with the same dimensions and the same electric resistivity.

\subsection{Temperature behaviour}

The specimens were placed in a six-layer permalloy shield with embedded temperature chamber. The impedance was measured by means of an auto-balancing RCL bridge HP4825A in the frequency range from $100 \mathrm{kHz}$ to $30 \mathrm{MHz}$.

During the impedance measurements, the temperature spans of -20 to $+77^{\circ} \mathrm{C}$ and -23 to $+82^{\circ} \mathrm{C}$ were used for the as-cast and the annealed sample, respectively. Fig. 2(a) shows the temperature dependence of impedance, $|Z| /\left|Z_{\mathrm{t} 0}\right|$, of the as-cast ribbon driven at frequencies up to $30 \mathrm{MHz}$. The impedance is normalized with respect to its room-temperature value $Z_{\mathrm{t} 0}$. One can see the increase of magnetoimpedance sensitivity to temperature with growing driving frequency. This correlation, however, differs for the annealed sample. The relative temperature change of impedance modulus $|Z|$ has maximum at $200 \mathrm{kHz}$ and, as it is shown in
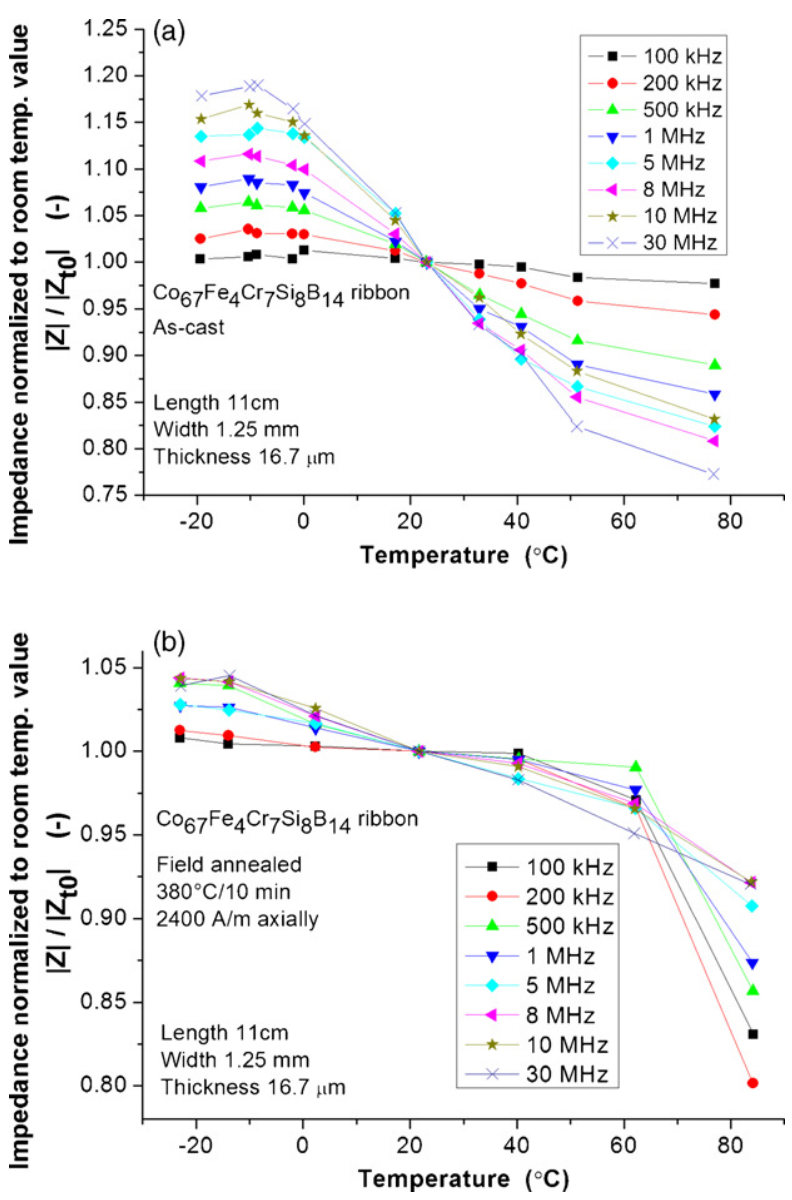

Fig. 2. Temperature change of impedance $Z$ normalized to the room temperature impedance $Z_{\mathrm{t} 0}$ : (a) as-cast sample and (b) field annealed sample.

Fig. 2(b), becomes significantly smaller for frequencies higher than $1 \mathrm{MHz}$.

Better comparison of the as-cast and the treated samples is shown in Fig. 3 where the temperature coefficients of impedance at different frequencies are plotted. Additionally, the real, $\operatorname{Re} Z$ (empty triangles), and the imaginary, $\operatorname{Im} Z$ (empty circles), parts of impedance $Z$ for the annealed sample are shown as well. The coefficients were calculated from maximal and minimal values of impedance in the temperature range from -20 to $+75^{\circ} \mathrm{C}$ and were related to the room temperature value (at $\left.21^{\circ} \mathrm{C}\right)$. One can see from

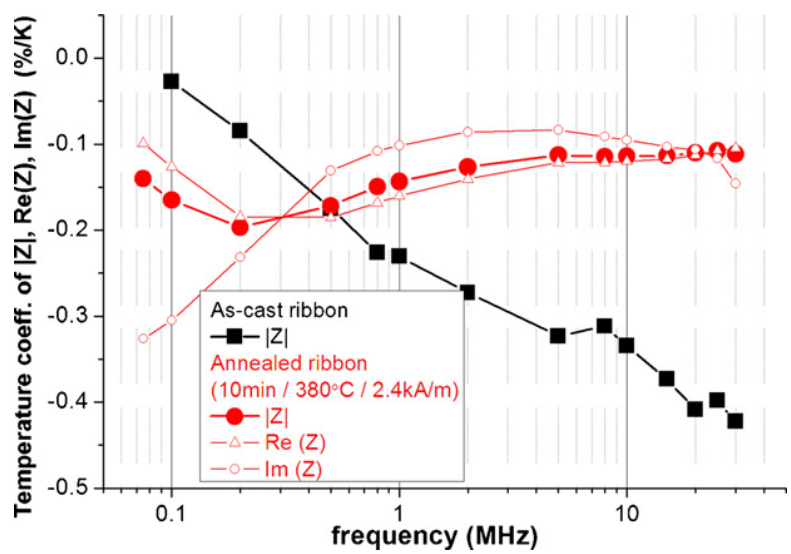

Fig. 3. Temperature coefficients of complex components of impedance $Z$ at given frequencies. 
the graph that the coefficients remain almost frequency invariant in case of the treated sample (full circles) and increase with frequency in case of the as-cast sample (full squares).

\subsection{GMI sensor}

When single-core GMI sensor is designed, the proper working point should be selected on the lateral part of GMI response by applying the bias field $H_{\mathrm{b}}$ [14,17]. Considering the GMI curve of the annealed sample shown in Fig. 1 we can assume sensitivity of $0.12 \Omega / \mathrm{A} / \mathrm{m}(0.096 \Omega / \mu \mathrm{T})$ at $1 \mathrm{MHz}$ for the suitable bias field $H_{\mathrm{b}}=15 \mathrm{~A} / \mathrm{m}$. Using given sensitivity and impedance drift (Fig. 3 ) of $-0.15 \% / \mathrm{K}$ (@ $1 \mathrm{MHz}$ ) the temperature offset drift of $-0.27 \mathrm{~A} / \mathrm{m} / \mathrm{K}$ $(-340 \mathrm{nT} / \mathrm{K})$ can be predicted.

Expected temperature offset drift of $-340 \mathrm{nT} / \mathrm{K}$ is in accordance with the value of $-409 \mathrm{nT} / \mathrm{K}$, which was experimentally achieved by Malátek et al. with a prototype of single-core GMI sensor employing the same annealed Co-rich ribbon [15]. Comparing the results with the amorphous microwire GMI sensor reported by Honkura [14] the treated Co-rich ribbon has almost three times lower temperature offset drift. Still, the value is too large to be suitable for precise magnetic sensors.

\subsection{Transverse permeability estimates}

Additional measurement of DC resistance was accomplished for the annealed specimen using the RLC bridge at its lowest frequency of $20 \mathrm{~Hz}$. In order to investigate the temperature dependence of resistivity, the specimen was placed again in the temperature chamber inside the permalloy shield. The temperature dependence of DC resistance in the temperature range from -25 to $+75^{\circ} \mathrm{C}$ is plotted in Fig. 4 (empty circles). In this particular alloy a very small negative linear temperature dependence of resistivity with a coefficient of $-0.005 \% / \mathrm{K}$ was observed. This negative coefficient can slightly enhance the skin depth and increase GMI effect with growing ambient temperature. This is, however, in contradiction with the observed temperature dependence of impedance modulus $|Z|$-see the measurement accomplished at $1 \mathrm{MHz}$ (full squares in Fig. 4).

There are three temperature-dependent quantities that can affect directly the impedance $Z$ : DC resistivity, thermal expansion and permeability in transverse (circumferential) direction. The observed negative resistivity coefficient, as it was mentioned above, would increase the impedance with growing temperature. The thermal expansion can, in the worst case, cause the change of impedance only about two orders lower than the measured one.

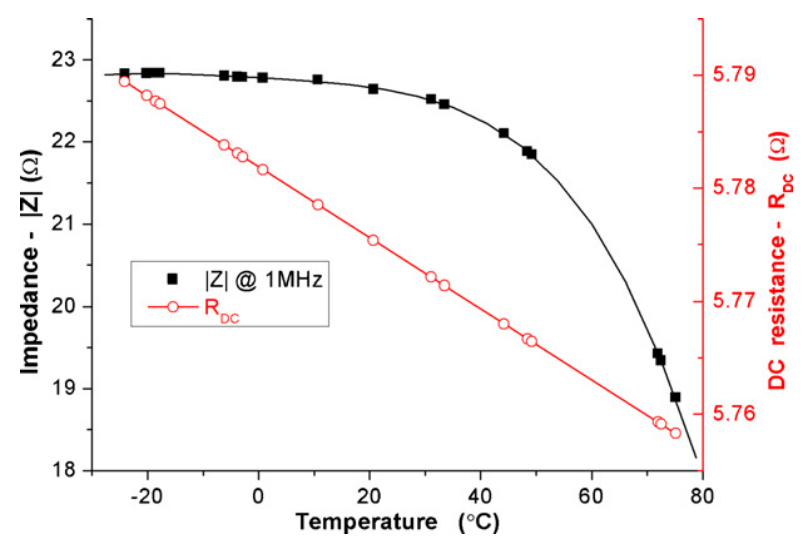

Fig. 4. Temperature dependences of resistance $R_{\mathrm{DC}}$ and impedance $|Z|$ of annealed sample measured at $1 \mathrm{MHz}$.

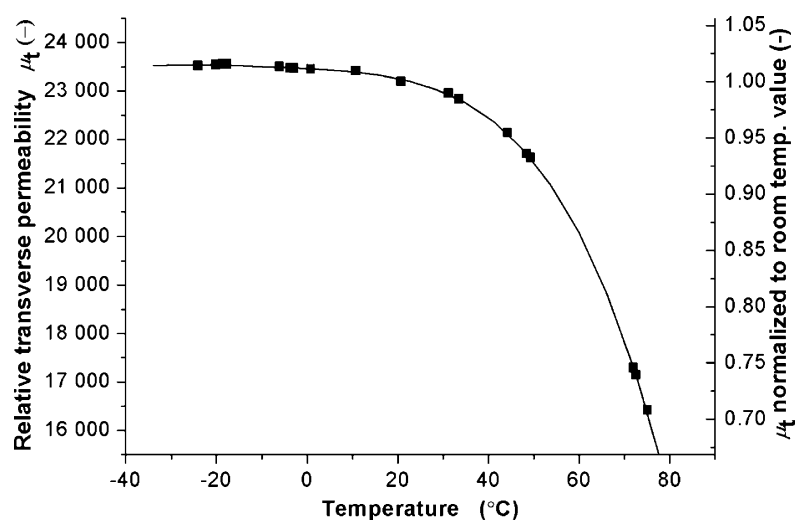

Fig. 5. Evaluated temperature characteristics of the relative transverse permeability at $1 \mathrm{MHz}$ for the treated material.

Thus it is expected that the dominant effect originates from the changes of transverse permeability $\mu_{\mathrm{t}}$.

To explain the temperature dependence of magnetoimpedance in this frequency region a simple electromagnetic model of GMI effect will be used [1]. Let us assume that the ribbon can be approximated by an infinite planar ferromagnetic conductor. The model can be described by a simplified formula for impedance then

$Z=R_{\mathrm{DC}} \frac{k \cdot t}{2} \cot \left(\frac{k \cdot t}{2}\right)$

where $t$ is the thickness, $R_{\mathrm{DC}}$ the DC resistance and the propagation constant $k$ is equal to $(1-j) / \delta$, where $\delta$ is penetration (skin) depth and $j$ is the imaginary unit.

Fig. 5 shows an estimate of the relative transverse permeability $\mu_{\mathrm{t}}$ with respect to ambient temperature. As can be seen, rapid decrease of the permeability $\mu_{\mathrm{t}}$ is observed for temperatures above $40^{\circ} \mathrm{C}$. It is worth mentioning that the compensation due to negative resistivity temperature coefficient is not negligible. While the transverse permeability $\mu_{\mathrm{t}}$ at $+80^{\circ} \mathrm{C}$ fall down below $70 \%$ of the room temperature value (see Fig. 5), the impedance modulus $|Z|$ at $1 \mathrm{MHz}$ decreases to only $87 \%$ of the reference value (downward triangle in Fig. 2(b)).

\section{Conclusions}

In this paper, we have discussed the problem of temperature stability of MI sensors, as shown on $\mathrm{Co}_{67} \mathrm{Fe}_{4} \mathrm{Cr}_{7} \mathrm{Si}_{8} \mathrm{~B}_{14}$ ribbons.

We also estimated temperature offset drift of the GMI sensor using this particular material. The huge temperature offset drift of $-0.27 \mathrm{~A} / \mathrm{m} / \mathrm{K}(-340 \mathrm{nT} / \mathrm{K})$ could be even larger for materials with positive resistivity temperature coefficient. This work also points out that:

- temperature stability is common problem for majority of GMI sensors;

- appropriate thermal treatments of amorphous materials should be carefully selected not only for the improvement of magnetic properties, but also with respect to the adjustment of temperature stability.

It is worth mentioning that the temperature drift of the offset could be also suppressed by an appropriate construction/operation of sensor using a double-core structure [15] or AC bias field $[16,17]$. Additional improvement of temperature stability can also be achieved by moving from classical GMI effect to one of the "offdiagonal magnetoimpedance" methods that sense the voltage from a pick-up coil instead of the voltage drop between the ends of the ferromagnetic sample $[7,14,17,18]$. 


\section{Acknowledgements}

The authors are grateful to Dr. Dušan Janičkovič of the Institute of Physics, Slovak Academy of Sciences, Bratislava for supplying the amorphous ribbons. The financial support from the research project AVOZ 10100520 is appreciated.The research of Pavel Ripka was supported by the program No. MSM6840770015 of the CTU in Prague sponsored by the Ministry of Education, Youth and Sports of the Czech Republic.

\section{References}

[1] M. Knobel, M. Vazquez, L. Kraus, in: K.H.J. Buschow (Ed.), Handbook of Magnetic Materials, vol. 15, North-Holland, 2003, pp. 497-563 (Chapter 5)

[2] P. Ripka (Ed.), Magnetic Sensors and Magnetometers, Artech House Publ., 2001.

[3] K. Mohri, T. Uchiyama, L.P. Shen, C.M. Cai, L.V. Panina, Y. Honkura, M. Yamamoto IEEE Trans. Magn. 38 (2002) 3063-3068.

[4] M. Malátek, A. Platil, P. Ripka, Eurosensors XVII. Guimaraes, University of Minho, Portugal, 2003, 418-419.

[5] I. Giouroudi, H. Hauser, L. Musiejovsky, J. Steurer, J. Appl. Phys. (2006), 99:08D906:1-6:3.

[6] M. Malátek, P. Ripka, L. Kraus, IEEE Trans. Magn. 41 (10) (2005) 3703-3705.

[7] www.aichi-mi.com.

[8] L.P. Shen, T. Uchiyama, K. Mohri, E. Kita, K. Bushida, IEEE Trans. Magn. 33 (5) (1997) 3355-3357.

[9] J.M. Blanco, A. Zhukov, A.P. Chen, A.F. Cobeno, A. Chizhik, J. Gonzales, J. Phys. D: Appl. Phys. 34 (6) (2001) L31-L34.

[10] K.R. Pirota, L. Kraus, H. Chiriac, M. Knobel, J. Magn. Magn. Mater. 226-230 (2001) 730-732.

[11] Y.K. Kim, W.S. Cho, T.K. Kim, C.O. Kim, J. Appl. Phys. 83 (11) (1998) 65756577.

[12] B. Jiang, N.A. Ulyanov, S.-C. Yu, J. Appl. Phys. 91 (10) (2002) 8444-8446.

[13] M.M. Tehranchi, M. Ghanaatshoar, S.M. Mohseni, M. Coisson, M. Vazquez, J. Non-Cryst. Solids 351 (2005) 2983-2986.

[14] Y. Honkura, J. Magn. Magn. Mater. 249 (2002) 375-381.
[15] M. Malátek, P. Ripka, Proceedings of the Eurosensors XIX, Barcelona, Spain, 2005, p. WPB45.

[16] M, Malátek, P. Ripka, IEEE Sensors, EXCO, Daegu, Korea, October 22-26, 2006, pp. 1012-1015.

[17] M. Malátek; Magnetic field sensors based on magnetoimpedance effects, $\mathrm{PhD}$ thesis, CTU in Prague, Prague, 2007.

[18] L. Kraus, M. Malátek, M. Dvořák, Sens. Actuat. A 142 (2008) 468-473.

\section{Biographies}

Michal Malátek was born in Ústí nad Orlicí, Czech Republic, in 1978. He received the Master degree in electrical engineering from Czech Technical University in Prague (CTU) in 2003, a PhD degree in 2008 from the same university. Since the year 2000 , his research has been focussed on giant magnetoimpedance in amorphous structures, magnetic measurements and development of magnetic sensors.

Pavel Ripka received an Ing. degree in 1984, a CSc (equivalent to PhD) in 1989 and Prof. degree in 2001 at the Czech Technical University (CTU), Prague, Czech Republic. He works at the Dept. of Measurement, Faculty of Electrical Engineering, CTU as a full professor, teaching courses in electrical measurements and instrumentation, engineering magnetism and sensors. He also worked as visiting scientist at Danish Technical University (1990-1993), National University of Ireland (2001) and in the Institute for the Protection and the Security of the Citizen, European Commission Joint Research Centre in Italy (2005/2006). His main research interests are magnetic measurements and magnetic sensors, especially fluxgate. He is a member of IEEE, Elektra Society, Czech Metrological Society, Czech National IMEKO Committee and Steering Committees of Eurosensors and SMM conferences. He served as an associate editor of the IEEE Sensors Journal. He was a General Chairman of Eurosensors 2002 conference.

Luděk Kraus was born in Frýdek-Místek, Czech Republic, in 1945. Graduated from the Faculty of Nuclear and Technical Physics, Czech Technical University in Prague, in 1968 from solid-state physics. Since 1968 he is with the Institute of Physics, Academy of Sciences of the Czech Republic, where he received the PhD degree in solidstate physics in 1980 . The main field of his research activities are the amorphous, nanocrystalline and nanocomposite soft magnetic materials and their applications. 